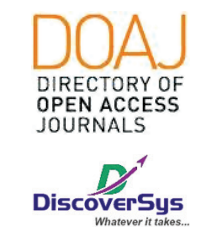

Published by DiscoverSys

\title{
Korelasi antara persentase lemak tubuh dan rasio lingkar pinggang-lingkar pinggul dengan kebugaran fisik pada mahasiswa Fakultas Kedokteran Universitas Mataram
}

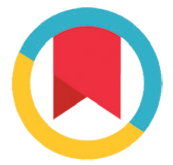

CrossMark

\author{
Ida Ayu Eka Widiastuti, ${ }^{1 *}$ Seto Priyambodo, ${ }^{2}$ Gede Wira Buanayuda ${ }^{3}$
}

\section{ABSTRACT}

Background: Body composition, is one of the factors that play a role in physical fitness. Body composition can be measured by calculating body fat percentage and waist-hip circumference ratio. Excessive body fat, usually will have a negative effect on physical fitness. The purpose of this study was to determine the correlation between body fat percentage and waist-hip circumference ratio with physical fitness.

Methods: This study is a descriptive analytic study with a cross sectional design. The subjects were 82 medical students of Universitas Mataram who met the research criteria. Body fat percentage was measured by body composition monitor and physical fitness obtained from maximal oxygen uptake values $\left(\mathrm{V}_{2 \max }\right)$ that were calculated from the results of the Queen College Step Test. Data were analyzed by using the Pearson correlation test.

Results: The results showed that the mean of body fat percentage, waist-hip circumference ratio, and $\mathrm{VO}_{2 \max }$ were $28.3 \mathrm{~kg} / \mathrm{m}^{2}, 0.87 \mathrm{~cm}$, and $37.7 \mathrm{ml} / \mathrm{kg} /$ minute, respectively. There was a significant correlation between body fat percentage and physical fitness $(p=$ $0.02 ; r=-0.256)$ while there was no significant correlation between the waist-hip circumference ratio and physical fitness $(p \geq 0.05$ ).

Conclusion: The higher the body fat percentage, the lower the level of physical fitness.

Keywords: body fat percentage, waist-hip circumference ratio, physical fitness, $\mathrm{V}_{2 \max }$

Cite This Article: Widiastuti, I.A.E., Priyambodo, S., Buanayuda, G.W. 2020. Korelasi antara persentase lemak tubuh dan rasio lingkar pingganglingkar pinggul dengan kebugaran fisik pada mahasiswa Fakultas Kedokteran Universitas Mataram. Intisari Sains Medis 11(2): 421-424. D0I: 10.15562/ism.v11i2.592

\section{ABSTRAK}

Latar belakang: Komposisi tubuh, merupakan salah satu faktor yang berperan dalam kebugaran fisik. Komposisi tubuh dapat diukur dengan menghitung persentase lemak tubuh dan rasio lingkar pinggang-lingkar pinggul. Seseorang yang memiliki kadar lemak tubuh yang berlebih, hampir selalu akan memberikan efek negatif terhadap kebugaran fisik. Tujuan penelitian ini adalah mengetahui korelasi antara persentase lemak tubuh dan rasio lingkar pingganglingkar pinggul dengan kebugaran fisik.

Metode: Penelitian ini merupakan penelitian analitik deskriptif dengan desain cross sectional. Subjek penelitian adalah 82 mahasiswi Fakultas Kedokteran Universitas Mataram yang memenuhi kriteria penelitian. Dilakukan pengukuran persentase lemak tubuh dengan body composition monitor, pengukuran lingkar pinggang dan pinggul, dan nilai kebugaran fisik diperoleh dari nilai ambilan oksigen maksimal $\left(\mathrm{V}_{2 \max }\right)$ yang dihitung dari hasil Queen College Step Test. Data dianalisis dengan menggunakan uji korelasi Pearson.

Hasil: Hasil penelitian menunjukkan bahwa rerata persentase lemak tubuh, rasio lingkar pinggang-lingkar pinggul, dan $\mathrm{V}_{2 \max }$ subjek masing-masing adalah $28,3 \mathrm{~kg} / \mathrm{m}^{2}, 0,87 \mathrm{~cm}$, dan $37,7 \mathrm{ml} / \mathrm{kg} /$ menit. Terdapat korelasi bermakna antara persentase lemak tubuh dengan kebugaran fisik ( $p=0,02 ; r=-0,256$ ) sementara tidak terdapat korelasi bermakna antara rasio lingkar pinggang-lingkar pinggul dengan kebugaran fisik.

Simpulan: Semakin tinggi persentase lemak tubuh maka semakin rendah tingkat kebugaran fisiknya.
Mataram, Mataram, Indonesia

${ }^{3}$ Departmen IImu Penyakit Dalam, Universitas Mataram, Mataram, Indonesia

\footnotetext{
*Korespondensi:

Ida Ayu Eka Widiastuti, Department Fisiologi, Universitas Mataram ayueka@unram.ac.id
}

Kata kunci: persentase lemak tubuh, rasio lingkar pinggang-pinggul, kebugaran fisik, $\mathrm{V}_{2 \text { max }}$ Cite Pasal Ini: Widiastuti, I.A.E., Priyambodo, S., Buanayuda, G.W. 2020. Korelasi antara persentase lemak tubuh dan rasio lingkar pingganglingkar pinggul dengan kebugaran fisik pada mahasiswa Fakultas Kedokteran Universitas Mataram. Intisari Sains Medis 11(2): 421-424. D0I: 10.15562/ism.v11i2.592

\section{PENDAHULUAN}

Kebugaran fisik merupakan kondisi yang harus dipenuhi untuk dapat menjalankan aktivitas sehari-hari dengan baik dan optimal. Kebugaran fisik dapat dicapai, salah satunya dengan melakukan 
aktivitas fisik yang memadai. Banyak penelitian di berbagai belahan dunia menunjukkan hasil bahwa telah terjadi penurunan dalam melakukan aktivitas fisik, meningkatnya angka kejadian obesitas, dan penyakit berisiko lainnya. ${ }^{1}$ Penurunan aktivitas fisik ini terjadi pada masa peralihan antara remaja akhir menuju masa dewasa awal, atau jika dikonversikan ke masa studi, maka hal tersebut terjadi saat memasuki bangku kuliah., ${ }^{2,3}$

Komposisi tubuh, merupakan salah satu faktor yang berperan dalam kebugaran fisik, di samping daya tahan jantung paru. Komposisi tubuh diukur dengan menghitung persentase lemak tubuh dan indeks massa tubuh. ${ }^{4}$ Metode lain untuk mengukur komposisi tubuh adalah dengan menggunakan rasio pinggang-pinggul (hip waist ratio). ${ }^{5}$ Indeks massa tubuh (IMT) merupakan pengukuran yang paling umum digunakan, baik dalam praktik klinik maupun kesehatan masyarakat, namun demikian IMT memiliki kelemahan karena tidak mempertimbangkan distribusi lemak tubuh yang berbeda antar individu dalam populasi. ${ }^{6}$

Tekanan darah tinggi, abnormalitas kadar lemak dalam darah, dan intoleransi glukosa, merupakan faktor-faktor risiko metabolik yang berhubungan dengan obesitas, yang dapat meningkatkan morbiditas dan mortalitas penyakit kardiovaskuler. ${ }^{7-10}$ Lingkar pinggang dan rasio lingkar pingganglingkar pinggul digunakan untuk memprediksi risiko penyakit-penyakit yang berhubungan dengan obesitas. ${ }^{11-13}$

Tingkat kebugaran kardiorespirasi berhubungan dengan timbunan adiposa pada daerah abdomen. Pada individu yang memiliki tingkat kebugaran kardiorespirasi sedang sampai tinggi memiliki timbunan lemak abdomen yang lebih rendah. ${ }^{14,15}$ Penelitian ini bertuuan untuk mengetahui korelasi antara persentase lemak tubuh dan rasio lingkar pinggang-lingkar pinggul dengan kebugaran fisik.

\section{METODE}

Penelitian ini merupakan penelitian analitik deskriptif dengan desain cross sectional. Subjek penelitian adalah 82 mahasiswi Fakultas Kedokteran Universitas Mataram tahap pre klinik yang memenuhi kriteria penelitian. Pengukuran persentase lemak tubuh dilakukan dengan menggunakan body composition monitor HBF-375. Lingkar pinggang diukur pada lingkar pinggang minimal, antara crista iliaca dan bagian terbawah kosta sedangkan lingkar pinggul diukur setinggi protrusi gluteal maksimal dengan menggunakan pita meteran. Rasio lingkar pinggang-lingkar pinggul ditentukan dari lingkar pinggang $(\mathrm{cm})$ dibagi dengan lingkar pinggul $(\mathrm{cm})$. Tingkat kebugaran fisik diperoleh dari nilai ambilan oksigen maksimal $\left(\mathrm{VO}_{2 \max }\right)$ yang yang merupakan nilai konversi dari pengukuran denyut nadi selama 15 menit setelah melakukan Queen's College Step Test, dengan menggunakan rumus.

Data hasil pengukuran dideskripsikan dalam bentuk rerata dan simpang baku. Uji korelasi antar variabel dilakukan dengan menggunakan uji korelasi Pearson. Hasil signifikan jika nilai p yang diperoleh kurang dari $0.05(\mathrm{p}<0.05)$.

\section{HASIL}

Seluruh subjek penelitian berjumlah 82 orang. Berdasarkan umur, maka rata-rata umur subjek adalah 19,7 tahun. Data deskriptif hasil pengukuran subjek disajikan pada Tabel 1 .

Pada Tabel 2 disajikan data hasil uji korelasi Pearson yang menghubungkan variabel kadar lemak tubuh dengan kebugaran fisik (kebugaran kardiorespirasi).

Dari hasil yang ditampilkan pada Tabel 2, tampak bahwa nilai $\mathrm{p}=0,020(\mathrm{p}<0,05)$. Jadi dapat disimpulkan bahwa terdapat korelasi yang bermakna antara kedua variabel tersebut. Nilai $r=-0,256$ menunjukkan korelasi negatif, dengan kekuatan korelasi lemah.

Pada Tabel 3 berikut ditunjukkan hasil uji korelasi Pearson yang menguji korelasi antara variabel rasio lingkar pinggang-lingkar pinggul dengan kebugaran fisik (kebugaran kardiorespirasi).

Dari hasil uji korelasi yang ditunjukkan pada Tabel 3, terlihat bahwa tidak terdapat korelasi yang bermakna antara rasio lingkar pinggang-lingkar pinggul dengan kebugaran fisik, dengan nilai $p=0,109(p \geq 0.05)$.

Tabel 1 Data deskriptif hasil pengukuran subjek penelitian

\begin{tabular}{llccc}
\hline Data pengukuran & N & Nilai maksimum & Nilai minimum & Rerata \pm SB \\
\hline Lingkar pinggang & 82 & 61,50 & 91,50 & $73,60 \pm 6,44$ \\
Lingkar pinggul & 82 & 72,50 & 100,50 & $84,16 \pm 5,97$ \\
Rasio lingkar pinggang-pinggul & 82 & 0,76 & 0,99 & $0,87 \pm 0,04$ \\
Persentase lemak tubuh & 82 & 19,80 & 37,00 & $28,34 \pm 3,98$ \\
$\mathrm{VO}_{2 \max }$ & 82 & 32,56 & 42,91 & $37,74 \pm 2,42$ \\
\hline
\end{tabular}


Tabel 2 Hasil uji korelasi antara persentase lemak tubuh dengan kebugaran fisik

\begin{tabular}{lccc}
\hline Variabel & N & R & p \\
\hline Persentase lemak tubuh & 82 & 0,256 & 0,020 \\
Kebugaran fisik $\left(\mathrm{VO}_{2 \max }\right)$ & 82 & & \\
\hline
\end{tabular}

Tabel 3 Hasil uji korelasi antara rasio lingkar pinggang-lingkar pinggul dengan kebugaran fisik

\begin{tabular}{llcc}
\hline Variabel & $\mathbf{N}$ & $\mathbf{r}$ & $\mathbf{p}$ \\
\hline Lingkar pinggang-pinggul & 82 & $-0,178$ & 0,109 \\
Kebugaran fisik $\left(\mathrm{VO}_{\text {2maks. }}\right)$ & 82 & & \\
\hline
\end{tabular}

\section{PEMBAHASAN}

Penelitian tentang korelasi persentase lemak tubuh dengan kebugaran fisik atau daya tahan kardiorespirasi menunjukkan hasil korelasi negatif, artinya semakin tinggi persentase lemak tubuh, maka tingkat kebugaran fisiknya makin rendah. ${ }^{16,17,18,19}$ Hal ini sejalan dengan hasil pada penelitian ini $(r=-0,256 ; p=0,020)$. Konsumsi oksigen per unit masa tubuh pada orang yang mengalami obesitas akan berkurang secara signifikan akibat jumlah lemak tubuh yang berlebihan, yang selanjutnya dapat memengaruhi fungsi jantung. Apabila terjadi akumulasi lemak di otot maka dapat menyebabkan pemakaian oksigen oleh otot tidak efektif sehingga mengakibatkan penurunan $\mathrm{VO}_{2 \max }{ }^{20}$

Penilaian obesitas dengan menggunakan rasio lingkar pinggang-lingkar panggul merupakan prediktor yang lebih baik bagi morbiditas akibat penyakit kardiovaskuler dan penyakit jantung coroner dibandingkan lingkar pinggang dan indeks massa tubuh. ${ }^{21}$ Pada laki-laki, rasio lingkar pinggang-lingkar pinggul $\geq 0,91$ memiliki hubungan dengan peningkatan kejadian penyakit koroner tiga kali lipat. ${ }^{22}$ Menurut WHO, rasio lingkar pinggang-lingkar panggul yang dikategorikan 'sehat' (healthy waist-hip ratio) adalah $\leq 0,85$ bagi perempuan dan $\leq 0,9$ bagi laki-laki. ${ }^{23}$

Dari 15 penelitian prospektif yang melibatkan 258.114 individu disimpulkan bahwa terdapat peningkatan risiko penyakit kardiovaskuler dengan meningkatnya lingkar pinggang ataupun rasio lingkar pinggang-lingkar pinggul, baik pada perempuan maupun laki-laki. Secara spesifik peningkatan $1 \mathrm{~cm}$ lingkar pinggang dan 0,01 rasio lingkar pinggang-lingkar pinggul, akan meningkatkan masing-masing $2 \%$ dan $5 \%$ risiko terhadap penyakit kardiovaskuler di kemudian hari. ${ }^{23}$ Kebugaran kardiorespirasi berhubungan dengan jumlah lemak total dan lemak di abdomen (abdominal adiposity). Terdapat korelasi yang kuat antara lemak total dengan kebugaran kardiorespirasi.
Individu dengan lemak total yang rendah memiliki tingkat kebugaran fisik (kardiorespirasi) yang tinggi. Demikian pula halnya dengan korelasi antara lemak di abdomen dengan kebugaran fisik, yaitu bahwa kebugaran tingkat sedang hingga tinggi dimiliki oleh individu dengan lemak abdomen yang rendah. ${ }^{24}$

\section{SIMPULAN}

Pada penelitian ini, didapatkan adanya korelasi yang bermakna antara persentase lemak tubuh dengan kebugaran fisik atau kebugaran kardiorespirasi. Semakin tinggi persentase lemak tubuh, maka semakin rendah tingkat kebugaran fisiknya, sementara untuk hubungan antara rasio lingkar pinggang-lingkar pinggul dengan kebugaran fisik tidak berhubungan signifikan.

\section{KONFLIK KEPENTINGAN}

Tidak terdapat konflik kepentingan terkait penelitian ini.

\section{PENDANAAN}

Seluruh pendanaan pada penelitian ini besaral dari pendanaan pribadi.

\section{KONTRIBUSI PENULIS}

Seluruh penulis terlibat dalam penyusunan, pelaksanaan, dan publikasi penelitian ini.

\section{DAFTAR PUSTAKA}

1. Faragas SP, Radu, LE, Vanvu G. The level of physical activity of university students. Procedia - Social and Behavioral Sciences. 2015;197:1454 - 1457.

2. Kwan MY, Cairney J, Faulkner GE, Pullenavegum EE. Physical activity and other health-risk behaviours during the transition into adulthood: A longitudinal cohort study. American Journal of Preventive Medicine. 2012;42(1):14-20.

3. Sigmundova D, Chmelik F, Sigmund E, Feltlova D, Fromel K. Physical activity in the lifestyle of Czech university students: Meeting health recommendations, European Journal of Sport Science. 2015;13(6);744-750.

4. Departemen Kesehatan Republik Indonesia. Panduan kesehatan olahraga bagi petugas kesehatan. Jakarta: Depkes RI. 2002.

5. Alimardani A, Beni MA, Dehesthi M, Alimardani M. Relationship between physical fitness and anthropometric indicators in non-athlete students. Annals of Biological Research. 2012;3(9):4617-4621.

6. Isomaa B, Almgren P, Tuomi T, Forsén B, Lahti K, Nissén M, Taskinen MR, Groop L. Cardiovascular morbidity and mortality associated with the metabolic syndrome. Diabetes Care. 2001;24:683-689.

7. Oda E, Kawai R. Age- and gender-related differences in correlations between abdominal obesity and obesity-related metabolic risk factors in Japanese. Intern Med. 2009;48:497-502. 
8. Whitlock G, Lewington S, Sherliker P, Clarke R, Emberson J, Halsey J, Qizilbash N, Collins R, Peto R. Body-mass index and cause-specific mortality in 900000 adults: collaborative analyses of 57 prospective studies. Lancet. 2009;373:1083-1096.

9. Sone H, Mizuno S, Fujii H, Yoshimura Y, Yamasaki Y, Ishibashi S, Katayama S, Saito Y, Ito H, Ohashi Y, Akanuma Y, Yamada N. Japan Diabetes Complications Study: Is the diagnosis of metabolic syndrome useful for predicting cardiovascular disease in asian diabetic patients? Analysis from the Japan Diabetes Complications Study. Diabetes Care. 2005;28:1463-1471.

10. Lakka HM, Laaksonen DE, Lakka TA, Niskanen LK, Kumpusalo E, Tuomilehto J, Salonen JT. The metabolic syndrome and total and cardiovascular disease mortality in middleaged men. JAMA. 2002;288:2709-2716.

11. Grundy SM, Brewer HB Jr, Cleeman JI, Smith SC Jr, Lenfant C. Definition of metabolic syndrome: Report of the National Heart, Lung, and Blood Institute/American Heart Association conference on scientific issues related to definition. Circulation. 2004;109:433-438.

12. World Health Organization. Reducing risks, promoting healthy life - The World Health Report. Geneva: World Health Organization. 2002.

13. Welborn TA, Dhaliwal SS, Bennett SA. Waist-hip ratio is the dominant risk factor predicting cardiovascular death in Australia. Med J Aust. 2003;179:580-585.

14. Gonzalez-Gross M, Castillo MJ, Moreno L, Nova E, GonzalezLamuno D, Perez-Llamas F et al. Alimentacion y valoracion del estado nutricional de los adolescentes espanoles (estudio AVENA). Evaluacion de riesgos y propuesta de intervencion. I. Descripcion metodologica del proyecto. Nutr Hosp. 2003;18:15-28.

15. Moreno LA, Joyanes M, Mesana MI, Gonzalez-Gross M, Gil CM, Sarria A et al. Harmonization of anthropometric measurements for a multicenter nutrition survey in Spanish adolescents. Nutrition. 2003;19:481-486.

16. Ghane M, Aghayari M, dan Mazreno AB. Body fat percentage in inactive students using anthropometric parameters. International Journal of Pediatrics. 2012;2(12):391-398.
17. Minasian V, Marandi SM, Kelishadi R, Abolhassani H. Correlation between aerobic fitness and body composition in middle school students. International Journal of Preventive Medicine. 2014;5(2):102-107.

18. Aphamis G, Giannaki CD, Tsouloupas CN, Ioannou Y, Hadjicharalambous M. The relationship between physical fitness and obesity among a sample of adolescents in Cyprus. Int J Adolesc Med Health. 2014;27(4):1-7.

19. Arabmokhtari R, Khazani A, Bayati M, Barmaki S, Fallah E. Relationship between body composition and cardiorespiratory fitness in students at postgraduate level. Zahedan J Res Med Sci. 2018;20(2):e12109.

20. Chatterjee S, Chatterjee P, Banyopadhyay A. Cardiorespiratory fitness of obese boys. Indian J Physiol Pharmacol. 2005,49(3):353-357.

21. Welborn TA, Dhaliwal SS, Bennet SA. Waist-hip ratio is the dominant risk factor predicting cardiovascular death in Australia. MJA. 2003;179:580-585.

22. Lakka HM, Lakksonen DE, Lakka TA, Niskanen LK, Kumpusalo E, Tuomihleto J, Salonen JT. The metabolic syndrome and total and cardiovascular disease mortality in midlle-aged man. JAMA. 2002;288(21):2709-2716.

23. Koning LD, Merchant AT, Pogue J, Anand SS. Waist circumference and wait-to-hip ratio as predictors of cardiovascular events: meta-regression analysis of prospective studies. European Heart Journal. 2007;28:850-856.

24. Ortega FB, Ruiz JR, Castillo MJ, Sjostrom M. Physical fitness in childhood and adolescence: a powerful marker of health. International Journal of Obesity. 2008;32:1-11.

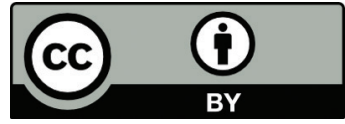

This work is licensed under a Creative Commons Attribution 